\title{
Evaluation of Lactation Promotion as Part of Baby Friendly Hospital
}

\author{
Arsani Lailatul Inayah ${ }^{1}$, Lina Handayani ${ }^{2}$, Azidanti Saufi ${ }^{3}$ \\ 1,2,3 Faculty of Public Health, Universitas Ahmad Dahlan, Yogyakarta, Indonesia
}

\begin{tabular}{|c|c|}
\hline Article Info & ABSTRACT \\
\hline & \multirow{8}{*}{$\begin{array}{l}\text { Decrease of maternal and infant mortality as well as increasing of the } \\
\text { exclusive breastfeeding are major public health priorities in Indonesia. In } \\
\text { decreasing the maternal and infant mortality, the government developed a } \\
\text { program for the community as Baby Friendly Hospital (BFH) to prevent the } \\
\text { effects, to support, and to promote breastfeeding. PKU Muhammadiyah } \\
\text { hospital in Yogyakarta was one of the BFH program managers. The purpose } \\
\text { of this study was to determine the breastfeeding promotion activities as part } \\
\text { of BFH at PKU Muhammadiyah Hospital in Yogyakarta.This was a } \\
\text { qualitative descriptive study. The findings of this study were inputs } \\
\text { consisting of 1) the knowledge and skills to better convey information } \\
\text { indicates the quality of human resources. 2) promotion of the policies for all } \\
\text { workers to reach the goal. 3) financial promotion is supported by the } \\
\text { operating system in the hospital. 4) supporting facility to promote lactation } \\
\text { leaflets, posters, ANC class, a breastfeeding counselor and nursing areas. } \\
\text { Implementation of lactation promotion was conducted in accordance with } \\
\text { program planning of BFH. }\end{array}$} \\
\hline Received Dec 02, 2016 & \\
\hline Revised Jan 29, 2017 & \\
\hline Accepted Feb 20, 2017 & \\
\hline Keyword: & \\
\hline Evaluation & \\
\hline Promotion of Breastfeeding & \\
\hline Baby Friendly Hospital & \\
\hline
\end{tabular}

Copyright () 2017 Institute of Advanced Engineering and Science. All rights reserved.

\section{Corresponding Author:}

Lina Handayani,

Faculty of Public Health,

Universitas Ahmad Dahlan,

Jl. Prof Soepomo, Janturan, Yogyakarta, Indonesia.

Email: linafkm@gmail.com

\section{INTRODUCTION}

Improving health of mothers and infants as well as efforts to reduce Maternal Mortality Rate (MMR) and Infant Mortality Rate (IMR) are still top prioritiess in the development of health [1]. 27\% provinces (9 provinces) showed the progressive increase in the infant mortality among tahun2007-2009 namely Aceh, Central Java, Yogyakarta, Central Kalimantan, Southeast Sulawesi, Gorontalo, North Maluku, Papua and West Papua [2]. The main targets of the National Medium Term Development Plan 2015-2019 is to improve health and nutrition status of mothers and children [3]. Giving of exclusive breastfeeding in developing countries managed to save about 1.5 million babies / year. On this basis, the World Health Organization (WHO) recommends exclusive breastfeeding to just give up babies aged 6 months it is described in Government Regulation No. 33 Year 2012 on Provision of BMS Exclusive. Infants with duration of six months breastfeeding or more have the survival of 33.3 times better than breast-fed for less than 4 months [4].

The Indonesian government issued PP 33 of 2012 on which emphasized the obligation of exclusive breastfeeding in nursing mothers on exclusive breastfeeding, exclusive breastfeeding was right for the baby after birth must be given by the mother unless there was a medical indication, no mother, mother was separated from the baby. Data IDHS 2012, the percentage Exclusive breast-fed infants (for infants under 6 months of age) was by $41 \%$, exclusive breastfeeding for infants aged $4-5$ months was by $27 \%$, and breastfeeding until the child in the age of 2 years was 55\% [5]. Coverage is still low exclusive breastfeeding 
can be increased either by education and self-awareness through the promotion of health. Wattimena and Hapsari (2014) suggested in a study of 45 people housewives showed that $84 \%$ of mothers who were touched by the torch and reading intervention managed successfully to breastfeed for more than six months [6]. This is in line with research of Dhandapany, et al (2008), better awareness of breastfeeding in mothers who were touched by the promotion of health than mothers who do not touch. An effort to protect, support and promote exclusive breastfeeding need support from GOI, local government, health care facilities and health personnel, community and family that the mother can give exclusive breastfeeding in infants with various programs [7]. One of them conducted through the hospital care for mothers and babies/ baby friendly hospital (BFH). BFH program has been implemented since 2001, with the hope to accelerate the decline in MMR and IMR. Hospitals can be categorized as Hospital Care for Mothers and Babies, when it meets the criteria for implementing the Policy 10 steps towards the protection of mothers and babies in an integrated and complete [1]. PKU Muhammadiyah Yogyakarta hospital is a hospital that implements programs to improve service quality BFH especially in the health care of mother and baby has been defined and ratified on December 8 , 2014 in a decree of the hospital director PKU Muhammadiyah Yogyakarta number 3966 / SK.3.2 / XII / 2014 [8].

\section{RESEARCH METHOD}

This study is qualitative descriptive. This design was chosen because the evaluation could see the key of success of BFH program at PKU Muhammadiyah Yogyakarta Hospital. Subjects numbered six people consisting of the promotion team lactation part obstetrics clinic, part of parturition, part of the baby's room, and three patients/ clients. Variables in the study were human resources, policies, funding, facilities, planning and implementation of promotional lactation. Instruments in this study were interview guide, checklist, stationery, cameras, tape recorders, and book notes.

\section{RESULTS AND DISCUSSION}

\subsection{Evaluation input}

The results showed the input of the promotion of lactation as part BFH program includes human resources (HR) policies and facilities.

\subsubsection{Human resources}

Human resources are the main components in an organization or activity. Suharto (2012) the quality of human resources plays a dominant role in determining the success or failure of an organization's performance. This means that an organization must have the appropriate human resources with the ability to do a productive job. Human resources of lactation sale at RS PKU Muhammadiyah Yogyakarta consisted of doctors, nurses, midwives, physiotherapists, nutrition and breastfeeding counselors in obstetric clinic, room baby, postpartum room, and a children's polyclinic. HR promotion of lactation is also a team BFH PONEK team. HR promotion of lactation is formed by a team of PONEK to run BFH program promotion section lactation. HR promotion of lactation has a duty to provide education about breastfeeding in patients/clients ranging from the ANC until parturition. The results of observations of researchers, human lactation promotion to educate well that with the delivery of clear, friendly, and create a comfortable atmosphere for the patient/client consultations. HR also neat appearance, the clothes are also in accordance with the teachings of Islam that is close the genitals.

Human resource is the greatest force in the processing of all income sources that exist on this earth, because basically the whole of God's creation before this earth was intentionally created by God for the benefit of mankind [10]. In an effort to increase the productivity of labor, training and development of knowledge and skills of human resources at RS PKU Muhammadiyah Yogyakarta conducted in accordance with human needs and also the needs of the community. As breastfeeding counselor training followed by promotion officer for four months of lactation, lactation management training, as well as training of health promotion. Training is also carried out if there are issues of maternal and infant health, such as on maternal prenatal, antenatal care. HR training is done in the hospital and outside the hospital as breastfeeding counselor training.

\subsubsection{Policies}

BFH program policies were set on December 8, 2014. This policy was created on the basis of the government program of BFH program. Policies made by the director of the hospital to support the Maternal and Infant health services. Policy BFH program at PKU Muhammadiyah Yogyakarta hospital refers BFH program implementation guidelines set by the government were the ten steps to protect the mother and baby

IJPHS Vol. 6, No. 1, March 2017: 45-50 
in an integrated and complete. Activity ten steps of the Maternal and Infant protection each has a SOP (standard operating procedure). Observation, informant interviews and review of documents for BFH programs are SOP lactation management, early initiation of breastfeeding SOP, SOP breastfeeding for baby cases section, SOP milk does not come out, rooming SOP, SOP formula. Lactation promotional activities that are discussed in this policy each have SOP is used as a reference implementation of the activities. Application of SOP basically as prevention of work accidents can happen anytime. As noted Awaluddin (2016) that the SOP is a standard or procedure that can provide information to workers in order to carry out their duties and responsibilities with a safe and comfortable so protected from disease or accident caused by work, and in order to achieve the goals set by the company [11].

\subsubsection{Funds}

Funds are also an important resource in an organization or activity. Planing budget for each activity is an important thing to do for the success of a program or activity; it is in line with research Paramita, et al (2015) that in an effort to improve their health status should optimize two things: human resources (personnel) and cost [12]. Funds or budget in health centers and hospitals can not yet be determined standards. However, as expected the health center or the District Health Office/ City and hospitals can provide funding / budget sufficient to carry out health promotion activities [13]. Marking of promotional activities lactation operational funds come from the hospital and also from cash PONEK team. Funding specifically for promotional activities is not specifically lactation. Budgetary funds and funds management followed BFH program funding procedures. Lactation promotion team did not know the details of budget funds given to the promotion of lactation. As an example for the procurement of the leaflet was coordinated by other teams, so do not know in detail how the budget is spent.

\subsubsection{Facility}

Facilities or infrastructure in the implementation of the promotion of lactation in RS PKU Muhammadiyah Yogyakarta are insufficient to patients or clients. As an example of means such as leaflets and there is therefore not yet reached the full scope of health promotion especially promotion of lactation. Means in the form of TV is not utilized either as a means of promotion, as most broadcast another TV show that is not about health education events. Health promotion with audio-visual media is a good medium in disseminating information [14]. In a study of health promotion using the medium of film is more effective in increasing knowledge than using media leaflet. According [15] media health education was made based on the principle that knowledge that exist in every human being received or captured through the five senses, the more senses used to receive something, the more and more clearly the knowledge acquired.

Infrastructure lactation promotional activities in RS PKU Muhammadiyah Yogyakarta ANC class there, a room for breast-feeding for patients or clients and also for hospital workers. Nursing areas according to the [16] is a room equipped with infrastructure breastfeeding and expressing milk used to feed the baby, express the milk, store expressed milk, and/ or counseling lactating/ breastfeeding. Based on the research room to breastfeed the child was in the room polikinik and inpatient sakinah with conditions comfortable enough and clean for the mother and baby. According to research [17] space for breastfeeding in hospital use is categorized health condition while in hospital. This is done to maintain hygiene and prevention of the spread of a disease that may be suffered by patients.

\subsection{Evaluation process}

Lactation promotion process starts with the planning of activities. According Wicaksono (2016) planning program made in accordance with the needs of society, so that the program implemented on target and provide a positive impact to people, the environment and the hospital [18]. Planning made aimed at the success of the activities carried out. Promotion of lactation in RS PKU Muhammadiyah Yogyakarta has no specific plans for promotional activities lactation is sub-activities of the program BFH. Planning activities that take place in accordance with BFH program that relies on the ten steps to protect the mother and baby. Planning made include lactation promotional activities to be undertaken, what strategies will be used to achieve the purpose of promotion, which will be targeted promotional activity, which activity will be carried out, taking into account the needs of the campaign targets. The implementation process is the promotion of lactation in RS PKU Muhammadiyah Yogyakarta done individually and in groups. Individually promotion can be performed when the mother began trimester antenatal one up to check the baby's mother. Promotion lactation do not only provide theoretical knowledge but also in the form of support for mothers are not susceptible to not give exclusive breastfeeding. Mothers who get good information or knowledge about breastfeeding, it is not easily affected [19].

These include the promotion of individual educational lactation, exclusive breastfeeding education, child development education and so forth. In the implementation of the patient allowed to ask any questions 
about pregnancy, breastfeeding, child growth are comfortable and relaxed, because the clerk put the concept of kinship in the delivery of information to the patient/ client. According Ambarwati, et al (2013) cooperation and good communication between the counselor and mother as well as the ability of the counselor's attitude is open and willing to be a good listener and create a cozy atmosphere will be able to explore the extent of knowledge of the mother and developing knowledge of the mother for the better [20].

\subsubsection{Evaluation output}

Promotional activities lactation in RS PKU Muhammadiyah Yogyakarta already covers the entire scope of the promotion of breastfeeding, such as pregnant women, nursing mothers both hospital patients and employees of PKU Muhammadiyah Hospital in Yogyakarta. Promotion lactation conducted by RS PKU Muhammadiyah Yogyakarta around hospital which included pregnant women, nursing mothers patients / clients as well as employees of the hospital. Based on the research overview of the output (output) the successful promotion of lactation as supporting the success of the program BFH have done well by the hospital team who not only consist of the promotion team of lactation but also other teams that assist in the implementation of activities such as public relations team, a team PKRS, team cleanliness and so forth. According [21] in his research said that the organization's activities can be effective if individuals and other groups working there interdependencies that could create a mutually supportive working relationship with each other, towards the achievement of organizational goals, strive to not make a difference which ended up being a conflict. This means that within an organization must create an atmosphere as comfortable as possible to achieve a common goal.Based on current research; program implementation BFH at RS PKU Muhammadiyah Yogyakarta is good enough. Especially the implementation of the promotion of lactation is done accordance with the stages of the implementation of the ten steps to protect the mother and baby in an integrated and complete towards the hospital dear Mother and Baby set by the Minister of Health Decree No. 603 / Menkes / SK / VII / 2008 on the Application of Program Guidelines Hospitals dear mother and Baby. However, there are some that have not been implemented by RS PKU Muhammadiyah Yogyakarta. The stages of the implementation of the promotion of lactation in $\mathrm{BFH}$ program is [1]:

1) There is a written policy about management support maternal and infant health services including early initiation of breastfeeding (IMD), exclusive breastfeeding and appropriate indications for formula feeding as well as kangaroo care method for low birth weight babies.

Implementation:

a) Breastfeeding including IMD is routinely communicated to health workers.

b) Cooperation with breastfeeding support groups and integrated in the territory of the referral process in order monev postpartum exclusive breastfeeding and PMK on LBW. In this phase of the RS PKU Muhammadiyah Yogyakarta have not implemented.

c) Each hospital has a lactation room and clinic with breastfeeding counselors are in place at work and outside of work hours can be contacted 24 hours. Breastfeeding counselor at RS PKU Muhammadiyah Yogyakarta can only be found during work hours and incidental although there has been a written schedule for each counselor.

2) Organizing antenatal care including maternal and neonatal health counseling, as well as breast-feeding counseling.

Implementation:

a) Provide information to pregnant women about the benefits of breastfeeding, lactation management including IMD and rooming, nutrition education and counseling "changes in maternal and fetal well as the needs of each trimester of pregnancy, childbirth, signs of danger".

b) All officers in obstetrics and child can provide information to mothers on how to breastfeed after birth right and the importance of breastfeeding.

3) Organize a clean delivery and safe as well as handling the newborn with early initiation of breastfeeding and maternal-infant skin contact.

Implementation:

a) The existence of lactation management training

4) Organize services a comprehensive emergency obstetric and neonatal care (PONEK) for 24 hours according to the minimum standards based on the type of hospital respectively.

Implementation:

a) Readiness obstetric care 24 hours

5) Providing adequate care for postpartum, rooming including helping nursing mothers the right, including teaching mothers how flushed ation for babies who can not suckle directly from their mother and did not leave the dairy ation through the bottle as well as neonatal care hospital.

Implementation:

a) management of lactation and infant care

IJPHS Vol. 6, No. 1, March $2017: 45-50$ 
b) The prohibition of promotion of infant formula in hospitals and the environment

6) Holding a two-way referral services and foster care referral network mothers and babies with other health facilities.

Implementation:

a) Organize training PONEK or other baby mother YanKes training for all officers concerned and to the health worker / midwife maternity hospital and private practice in the scope of the referral.

7) Holding the infant immunization services and growth.

Implementation:

a) Monitor and commercialize exclusive breastfeeding in infants

8) Organize family planning health services, including prevention and management of unwanted pregnancies and other reproductive health.

9) Organize maternal and perinatal audits hospital periodically and follow-up. Implementation:

a) Do the intervention and follow-up in reducing Maternal Mortality Rate and Infant Mortality Rate

10)Empower support group ation in following exclusive breastfeeding and PMK.

Implementation:

a) The existence of hospital auxiliaries as support breastfeeding and PMK, where group members will help and support exclusive breastfeeding, including the implementation of the FMD

$\mathrm{BFH}$ program implementation has been conducted throughout the country for the welfare of its people, and is proven to increase public knowledge about breastfeeding and also about other pregnancy problems. This is in line with research Brackett (2014) who wanted to see how useful BFH for the welfare of mother and baby as well as the development of the US state, stating that the program BFH can promote or demonstrate on breastfeeding is beneficial to long-term health as well as the program BFH is not only beneficial to the welfare mother and baby, but both beneficial for the country as a whole [22].

Based on research Braun, et al (2003) said that the implementation BFH (The Baby-Friendly Hospital Initiative) can increase the rate of breastfeeding and exclusive breastfeeding [23]. However in order to be universal breastfeeding, it is necessary to strengthen $\mathrm{BFH}$ and to develop other interventions intended to protect, promote, and support breastfeeding practices. Research Abrahams and Labbok (2009) states that the implementation BFH can have a positive impact in that exclusive breastfeeding will result in improved child health and survival [24]. This means that the implementation of the program BFH or BFH giving an increased role in the exclusive breasfeeding coverage in any country that is implementing this program, resulting in an increase in the degree of public health.

Implementation of the program is done well BFH also provide benefits for the hospital itself, particularly in the implementation of the promotion of lactation. Promotion lactation do provide benefits, the hospital is achieving the goal of improving community health status. Implementation of promotion of lactation as part BFH program to increase knowledge about breastfeeding mothers and also about child development as well, so the infant or child is born can be a quality human resources for the generation of national development.

\section{CONCLUSION}

Input the quality of human resources promotion of lactation has been good, the views from the knowledge and skill in disseminating information to patients. Promotion of lactation policy set together with the policy set BFH programs and policies that have been made have been socialized to all officers. The policy set is one of the efforts to increase the coverage of exclusive breastfeeding. Funding lactation promotional activities derived from the operational fund hospitals. Management of funds made by the hospital concerned in accordance with the needs. Facilities that support the promotion of lactation is no leaflets, posters, ANC class, a breastfeeding counselor and nursing areas. Amenities treated both for the convenience of the patient / client. The implementation process from the planning stage of lactation promotion activities carried out by the team BFH. Planning made by considering needs of the community or patient (pregnant and lactating mothers). The promotion of lactation done to individuals and also groups, the media used are leaflets, posters, procurement ANC classes, breastfeeding counseling, lactation counseling is done every three months. Output the successful program implemented BFH RS PKU Muhammadiyah key is the commitment and cooperation of officers to increase the coverage of exclusive breastfeeding.

\section{REFERENCES}

[1] Health RI, "The regulation of the Minister of health of the Republic of Indonesia No. 004 in 2012 about technical guide health promotion hospitals," 2012.

[2] Ministry of Health, "Health statistics: Health profile of Indonesia," Jakarta, 2013. 
[3] Health RI, 'The decision of the Minister of health RI No.HK. 02/MENKES/52/2015 about Health responsible building sign," 2015.

[4] B. Nurmiati, "Influence the duration of breast feeding Against Infant Survival in Indonesia," Jurnal Makara Health, vol/issue: 12(2), pp. 47-52, 2008.

[5] Health RI, "Director-General of Community nutrition and maternal and child health Nursing Home Launches," 2014. http://www.depkes.go.id retrieved on March 9, 2016.

[6] I. Wattimena and E. W. Hapsari, "The effectiveness of Interventions and Counselling Readings in nursing mothers," Journal Ners Lantern, vol. 7, pp. 19-29, 2014.

[7] G. Dhandapany, et al., "Pregnancy counseling Beastfeeding-it Adequate?" International Journal of nursing, vol/issue: 3(5), pp. 1-4, 2008.

[8] "The decision letter of Director of PKU Muhammadiyah Yogyakarta Number 3966 about Hospital Policies dear to mothers and babies."

[9] A. A. Suharto, "The influence of the quality of human resources, your understanding and Wow, there's a cake on performance Clerk on the District Inspectorate of Kediri," The journal management science, vol/issue: 1(3), pp. 6779, 2012.

[10] D. Haluty, "Islamic and human resource management," Journal of quality Irfani, vol/issue: 10(1), pp. 63-74, 2014.

[11] Y. F. Awaluddin, "The standard understanding of Operational Analysis procedure (SOP) the safety and occupational health (K3) on the Unit the means of PT. Train Indonesia (Persero) Regional Operations (including Daop) VI Yogyakarta," University theses, Ahmad Dahlan in Yogyakarta, 2016.

[12] A. Paramita, et al., "The implementation of the programme of Breast Milk Exclusive Thun 2013 in Probolinggo Clinics," Health systems Journal, vol/issue: 18(03), pp. 267-276, 2015.

[13] B. Hartono, "The promotion of health in Clinics, hospitals," Jakarta, Rineka Copyright, 2010.

[14] B. Suhertusi, et al., "On the influence of Media promotion of health Breast Milk Exclusively against Wali Mother in Knowledge work-area Clinics Bottom Begalung, Padang," Health Journal Andalas, vol/issue: 4(1), pp. 17-22, 2014.

[15] S. Notoadmodjo, "Education and behavioral health," Jakarta, Rineka Copyright, 2003.

[16] Regulation of the Minister of health of Indonesia number 152013 of the Ordinance the provision of Specialized Nursing Facilities and/or Flushed breast milk.

[17] U. A. Ruki, "The importance of maternal and child Spaces As supporters of Nursing Facilities in public areas," $A$ Humanities Journal, vol/issue: 7(29), pp. 110-121, 2011.

[18] M. C. Wicaksono, "Program Management analysis of Corporate Social Responsibility (CSR) in Bantul Hospital Nur Hidayah," University theses, Ahmad Dahlan in Yogyakarta, 2016.

[19] W. Amen, et al., "The influence of Social Factors of the mother towards the success of Breast-feeding in the first two months," Journal of medicine Brawijaya, vol/issue: 28(2), pp. 146-151, 2014.

[20] R. Ambarwati, et al., "Lactation Counseling Intensive Influence against breast milk Fund Exclusive 3 months," Journal of nutrition Indonesia, vol/issue: 2(1), pp. 15-23, 2013.

[21] S. Wartini, "Conflict Management Strategies in an effort to Maningkatkan the performance of produce educators work together," Journal of management and organization, vol/issue: 6(1), pp. 64-73, 2015.

[22] K. Brackett, "The baby friendly initiative," thesis, Liberty University, 2014.

[23] M. L. G. Braun, et al., "Evaluation of the impact of the baby-friendly Hospital Initiative at the level of nursing," Journal of Am J public health, vol/issue: 98(8), pp. 1277-1279, 2003.

[24] S. W. Abrahams and M. H. Labbok, "Exploring the impact of the baby-friendly Hospital Initiative on trends in breast milk exclusively," Breasfeeding International Journal, vol/issue: 4(11), 2009. 